\title{
Anosmia Following Head Trauma: Preliminary Study of Steroid Treatment
}

\author{
Katsuhisa Ikeda, Takashi Sakurada, Tomonori \\ Takasaka, Takuji OKItsu* and Shinji Yoshida* \\ Department of Otolaryngology, Tohoku University School of \\ Medicine, Sendai 980-7\%, and *Department of \\ Otolaryngology, Sendai City Hospital, Sendai 980
}

Ikeda, K., Sakurada, T., Takasaka, T., Okitsu, T. and Yoshida, S. Anosmia Following Head Trauma: Preliminary Study of Steroid Treatment. Tohoku J. Exp. Med., 1995, 177 (4), 343-351 — Twenty patients with posttraumatic anosmia were subjected to olfactory function testing, including olfactory acuity tests using a $\mathrm{T} \& \mathrm{~T}$ olfactometer and an intravenous olfaction test. T \& T tests revealed complete loss in 14 patients. In the intravenous olfaction test, 14 patients showed no response and 5 patients showed abnormal responses. The severity of olfactory dysfunction showed no correlation with background factors such as the site of head trauma, the presence of the fracture of skull, the presence of unconsciousness, or the presence of head operation. As a preliminary study, seventeen patients were administered a corticosteroid, a topical nasal drop of $0.1 \%$ betamethasone for 12 patients and an oral administration of prednisolone for 5 patients. Four patients showed slight recovery of olfactory function following a corticosteroid therapy. Effects of corticosteroids on olfaction might be explained by regeneration of olfactory receptor cell axons and reestablishment of contact with cells in the olfactory bulb. —— anosmia; head trauma; corticosteroid

Olfactory dysfunction following head trauma is frequently overlooked because of main attention paid to head injuries. Difficulty in early detection of anosmia and presumed involvement of injury or tearing of the olfactory nerve fibers in posttraumatic anosmia may result in a poor prognosis (Summer 1964; Hagen 1967; Kimura et al. 1991).

The present study was aimed at retrospective analysis of olfactory dysfunction following head trauma in order to assess prognostic factors. Furthermore, systemic administration of corticosteroids may provide a new insight into the improvement of olfactory acuity.

\section{Subjects And Methods}

Twenty patients with posttraumatic anosmia were subjected to olfactory

Received June 8, 1995; revision accepted for publication October 21, 1995.

Address for reprints: Katsuhisa Ikeda, M.D., Department of Otolaryngology, Tohoku

University School of Medicine, 1-1 Seiryomachi, Aoba-ku, Sendai 980-77, Japan. 
function tests. The age ranged from 9 to 78 years and there were 12 males and 8 females (Fig. 1). Transport olfactory loss resulting from mechanical injuries in the nose was excluded in all patients by anterior rhinoscopy and radiological images.

The olfactory acuity tests were performed using a $\mathrm{T} \& \mathrm{~T}$ olfactometer (Takasago Industry, Tokyo) as described by Zusho et al. (1981). The subject smelled a strip of paper soaked with one of the five standard odorants, i.e. $\beta$-phenyl ethyl alcohol (odorant A), cyclotene (B), isovaleric acid (C), $\gamma$-undecalactone (D) and scatole $(\mathrm{E})$. The odorants were diluted and there were eight degrees of concentration, each of which differed by a magnitude of 10 . The test was successively performed from odorant $\mathrm{A}$ to $\mathrm{E}$ without olfactory fatigue. The minimum concentration at which an odorant was sensed was termed the detection threshold. The point at which the minimum concentration of an odorant could be qualitatively judged was termed the recognition threshold. The subject could be required to match odorants to responses on a questionnaire. Results were compiled in the olfactogram, in which grades -2 and 5 (ordinates) show the minimum and maximum concentrations of each odorant, respectively, except for odorant $\mathrm{B}$ whose maximum is 4 . The threshold was defined as 6 except for odorant $\mathrm{B}$ when the maximum concentration was not sensed. The detection threshold was located around score 0 and the recognition threshold around 1 in normal. The severity of olfactory function based on the recognition threshold was defined mild disturbance as scores 1.1 to 2.5 , moderate as 2.6 to 4.0 , severe as 4.1 to 5.5 , and no response.

An intravenous olfaction test (Ikeda et al. 1988) was performed using the

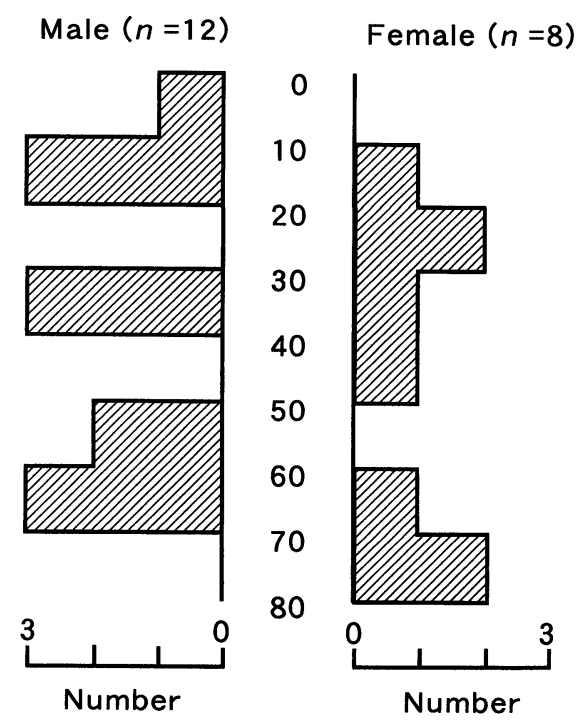

Fig. 1. Disturbance of age and sex in patients with posttraumatic anosmia. 
following procedure. Ten milligrams thiamine propyl disulphide (Alinamin ${ }^{\circledR}$, Takeda Pharmacy, Osaka) solution was administered through the median vein of the left arm for $20 \mathrm{sec}$ during normal nasal breathing. The latent time was defined from the starting point of the injection to the point of sensing an odorant. The duration time was defined from the beginning of sensation to the point of losing an odorant. In normal subjects, the latent and the duration times were seven to eight and 60 to $90 \mathrm{sec}$, respectively.

Seventeen patients were subjected to corticosteroid treatment, with a topical nasal drop of $0.1 \%$ betamethasone for 12 patients and an oral administration of prednisolone for 5 patients. A few drops of betamethasone were applied to the superior part of the nasal cavity by use of the head down position twice a day. A short course (10 to 14 days) of systemic corticosteroids started at 30 to $60 \mathrm{mg}$ per day with a quick taper. The duration of follow-up following corticosteroid treatment ranged between 6 and 12 months.

The data values are expressed as the mean \pm s.D. Statistical analysis was performed by chi-square test and $p<0.05$ was accepted as significant.

\section{RESULTS}

\section{Case report}

An 11-year-old boy encountered traffic accident in 1989. He went into a coma and received skull base surgery in the frontal region immediately after head injury. His consciousness was resumed several days after operation. He complained of olfactory dysfunction about 2 months postinjury. An intravenous olfaction test, which was taken 3 months after head trauma, showed no response. About 2 years later, he was referred to our clinic in order to evaluate detailed examinations and possible treatment for anosmia. $\mathrm{T} \& \mathrm{~T}$ olfactometer showed

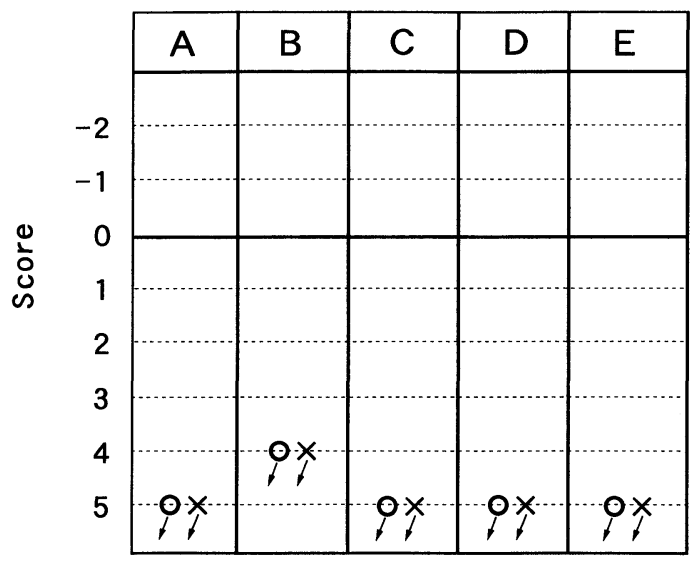

Fig. 2. Olfactory acuity before corticosteroid treatment. $\bigcirc$ the detection threshold; $\times$ the recognition threshold; $\downarrow$ no response. 


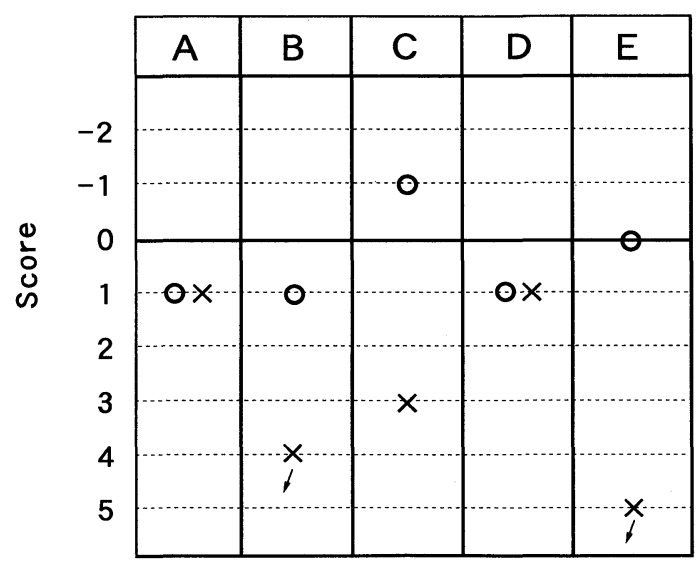

Fig. 3. Olfactory acuity after corticosteroid treatment. $\bigcirc$ the detection threshold; $\times$ the recognition threshold; $\downarrow$ no response.

severe damage of olfaction (Fig. 2). No response was obtained by an intravenous olfaction test.

Oral administration of prednisolone was initiated from $30 \mathrm{mg}$ per day, followed by a quick taper for 12 days. After corticosteroid treatment, his olfactory acuity was remarkably improved; detection and recognition thresholds were 0.4 and 3.2 in averaged scores (Fig. 3), respectively, and the latent and duration time of an intravenous olfactory test was 25 and $49 \mathrm{sec}$, respectively. During a followup of ten months, his olfaction has been almost unchanged.

\section{Periods from injuries}

Fig. 4 shows the periods from head trauma to subjective complaint of anosmia and to consultation to ear-nose-throat (ENT) clinic. Half of the patients felt their anosmia within 1 month postinjury whereas most of the patients required a

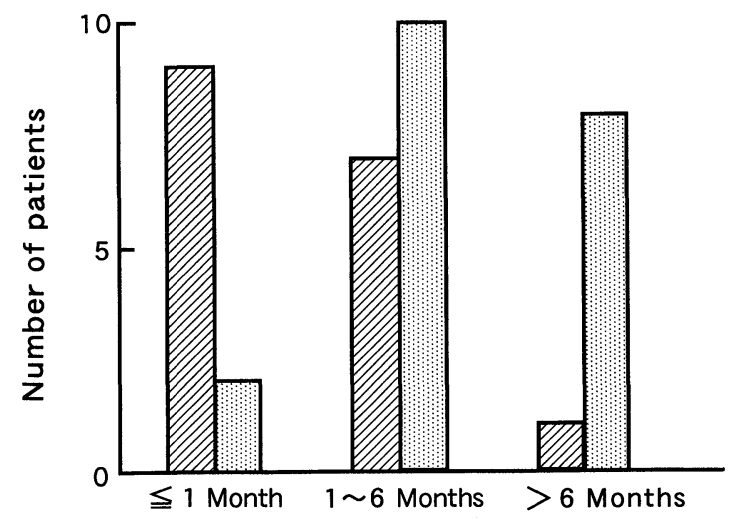

Fig. 4. Periods from head trauma to subjective complaint of anosmia (hatched columns) and to ENT consultation (dotted columns). 
longer period for receiving reliable assessment of olfactory dysfunction in ENT clinic.

\section{Olfactory tests}

Nineteen of the 20 patients received olfactory function tests. $\mathrm{T} \& \mathrm{~T}$ olfactometer revealed a complete loss in 14 patients, severe damage in 4 patients, and moderate damage in 1 patient. In an intravenous olfaction test, 14 patients showed no response, and 5 patients showed a prolongation in the latent time $(14.2 \pm 8.4 \mathrm{sec}, n=5)$ and a reduction in the duration time $(30.8 \pm 19.9 \mathrm{sec}, n=5)$.

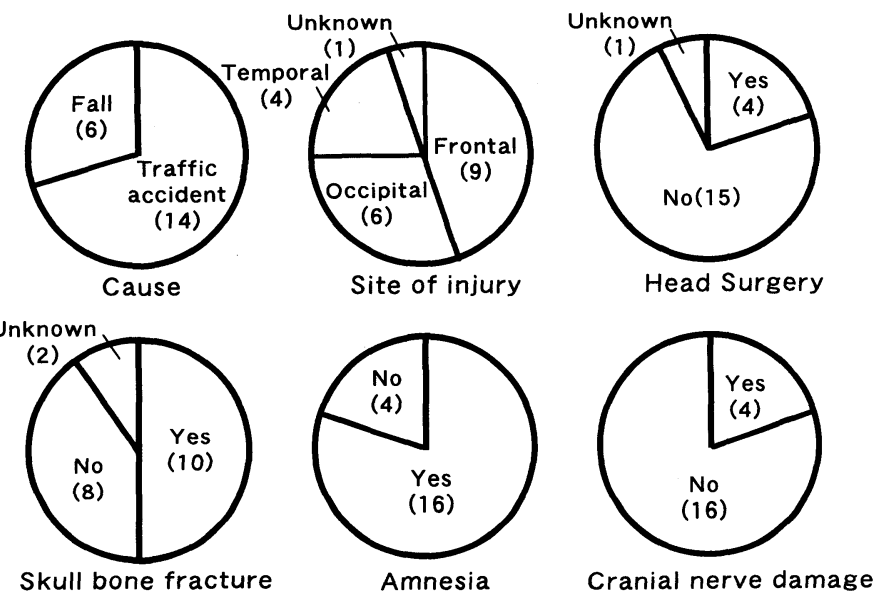

Fig. 5. Backgrounds of patients with posttraumatic anosmia.
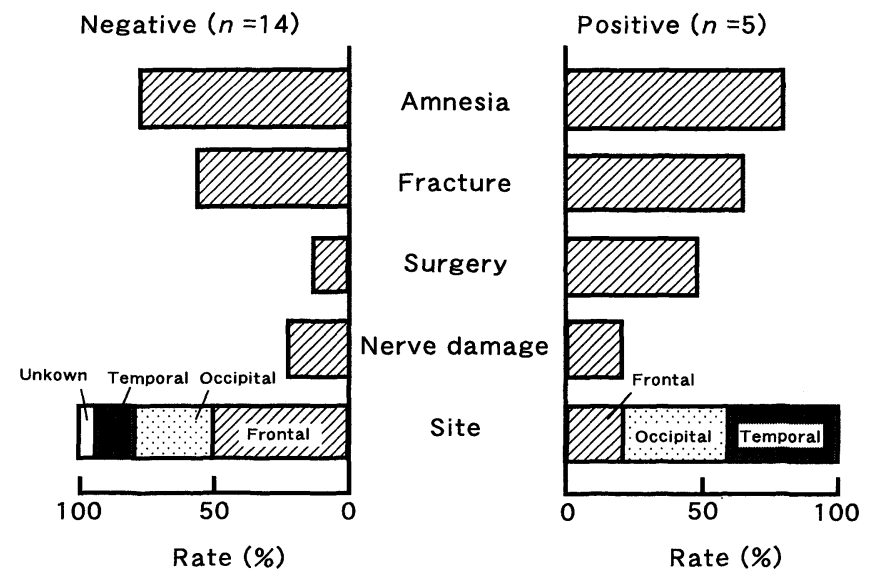

Fig. 6. Relationship between an intravenous olfactory test and background factors of head trauma. 


\section{Background factors}

Fig. 5 shows background factors of patients with posttraumatic anosmia. The severity of olfactory dysfunction determined by an intravenous test showed no correlation with the background factors described here (Fig. 6).

\section{Effects of corticosteroids}

No patients showed subjective improvement in olfactory acuity before visiting at our clinic. Three out of 5 patients with oral administration and one out of 12 patients with topical application in corticosteroid treatment showed a significant recovery of olfactory function. Fig. 7 shows an improvement of olfaction in recognition threshold of $\mathrm{T} \& \mathrm{~T}$ olfactometer and duration time of an intravenous test. However, no improvement was observed in 13 patients with corticosteroid treatment.

Table 1 shows backgrounds of head trauma and results of olfactory acuity
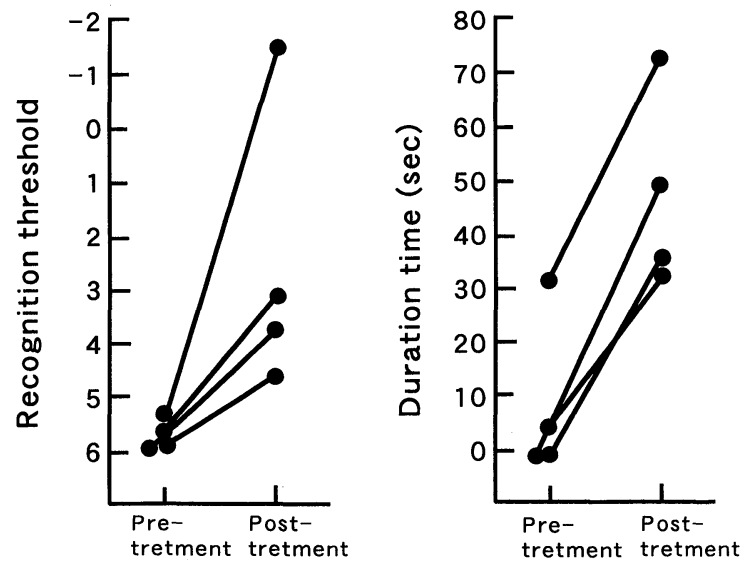

Fig. 7. Changes in olfactory acuity following corticosteroid treatment.

TABLE 1. Backgrounds of patients with improved olfactory function

\begin{tabular}{cccccccc}
\hline Case & Amnesia & Fracture & $\begin{array}{c}\text { Head } \\
\text { surgery }\end{array}$ & $\begin{array}{c}\text { Cranial } \\
\text { nerve damage }\end{array}$ & $\begin{array}{c}\text { Site of } \\
\text { brain damage }\end{array}$ & $\begin{array}{c}\text { Olfaction } \\
\text { score }^{\mathrm{a}}\end{array}$ & \begin{tabular}{c} 
Postinjury $_{\text {period }^{\mathrm{b}}}$ \\
\hline$\# 1$
\end{tabular} \\
\hline+ & + & + & + & Frontal & 5.8 & 24 \\
$\# 2$ & + & + & - & + & Occipital & 5.6 & 1 \\
$\# 3$ & + & - & + & - & Occipital & 5.2 & 24 \\
$\# 4$ & + & - & - & - & Temporal & 5.8 & 240 \\
\hline
\end{tabular}

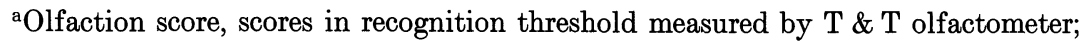

${ }^{b}$ Postinjury period, the period from head trauma to corticosteroid treatment (months).

+ presence; - absence. 


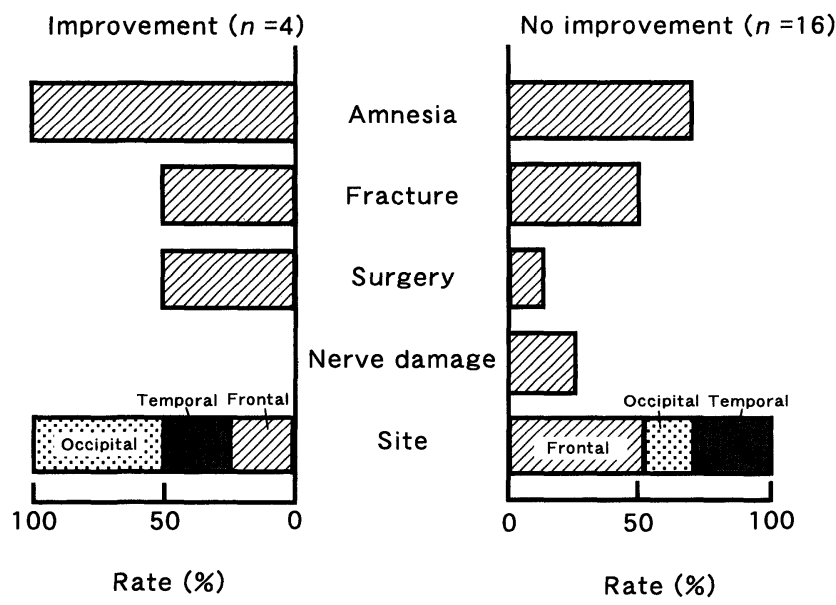

Fig. 8. Relationship between backgrounds of head trauma and prognosis of olfaction.

tests before treatment in patients with improved olfactory function. All of the patients took a transient unconsciousness without accompanying damage of cranial nerves. A variety of postinjury periods were noted. When the backgrounds of head trauma were correlated with the prognosis of olfaction, none proved to have a significant effect on prognosis (Fig. 8). Postinjury periods were $72.3 \pm 97.3$ months $(n=4)$ for improved patients and $22.4 \pm 58.6(n=15)$ for unimproved patients, which did not indicate a significant difference. Scores in recognition threshold measured by $\mathrm{T} \& \mathrm{~T}$ olfactometer before treatment showed no significant difference between the two groups; $5.6 \pm 0.2(n=4)$ for recovered patients and $5.5 \pm 0.6(n=15)$ for unrecovered patients.

\section{Discussion}

Neural mechanisms for posttraumatic anosmia can be categorized as i) injury of the olfactory nerve fibers and ii) injury of olfactory brain regions. Early improvement in anosmia was suggested to result from removal of hematoma or edema in olfactory brain centers (Summer 1975). The present patients, who had received a relatively long-term follow-up before our consultation, failed to recover olfactory loss, suggesting the damage of neural tissues. The incidence of anosmia was reported to increase with the severity of injuries (Summer 1964). Occipital and frontal impact injuries were likely to result in anosmia (Leigh 1943; Summer 1964; Zusho 1982). These findings suggest that head injuries of severe degree in frontal and occipital regions are signs for a poor prognosis. In the present study, although the major sites of injury were frontal and occipital regions, the prognosis for olfaction was not related with the site of injury. The site of injury may be independent on the prognosis for olfaction. Severe head injuries indicated by the presence of amnesia, skull base fracture and intracranial operation showed no 
correlation with the prognosis. Moreover, the severity of olfactory loss is not correlated with the prognosis. These findings indicate that the prognosis is not determined by the severity of either head injuries or anosmia, which is consistent with the previous report (Zusho 1982). Several studies (Summer 1964; Costanzo and Becker 1986) suggest that recovery becomes less expectable with time. Beyond 6 months to a year the prognosis for recovery was very poor, indicating an irreversible damage in olfactory neural tissues. Our results showed no relation between the prognosis and the posttraumatic period. This may be explained by the fact that most of the patients were referred to our clinic after a year following injury.

So far, therapeutic trials for posttraumatic anosmia have not yet been attempted. We used corticosteroids as treatment regimen for the olfactory impairment. Topical application of corticosteroids, presumably getting direct access to olfactory receptor cells, did not show a significant efficacy except for one patient. However, even in a preliminary study, systemic administration of corticosteroids appeared to be apparently efficacious in the treatment of posttraumatic anosmia. Since in case \#2 shown in Table 1 were corticosteroids initiated one month postinjury, the effectiveness of corticosteroids may be masked by a spontaneous improvement of olfaction. However, improvement of olfaction in other 2 cases, who took a long duration following injury, is more likely to be due to action of corticosteroids on olfactory neural tissues. Although exact mechanisms of corticosteroids in improved olfaction are unknown, regeneration in olfactory receptor cells might result in reestablishment of contact with cells in the olfactory bulb as determined in animal experiments (Nagahara 1940; Graziadei and Graziadei 1979).

\section{References}

1) Costanzo, R.M. \& Becker, D.P. (1986) Smell and taste disorders in head injury and neurosurgery patients. In: Clinical Measurements of Taste and Smell, edited by H.L. Meiselman \& R.S. Rivlin, MacMillan Publishing Company, New York, pp. 565578.

2) Graziadei, P.P.C. \& Graziadei, G.A.M. (1979) Neurogenesis and neuron regeneration in the olfactory system of mammals. I. Morphological aspects of differentiation and structural organization of the olfactory sensory neurons. J. Neurocytol., 8, 1-18.

3) Hagen, P.J. (1967) Posttraumatic anosmia. Arch. Otolaryngol., 85, 107-111.

4) Ikeda, K., Sakurada, T., Sasaki, Y., Takasaka, T. \& Furukawa, Y. (1988) Clinical investigation of olfactory and auditory function in type I pseudohypoparathyroidism: participation of adenylate cyclase system. J. Laryngol. Otol., 102, 1111-1114.

5) Kimura, K., Miwa, T., Donjyo, T., Furukawa, M. \& Kamide, M. (1991) Clinical observation on post-traumatic anosmia. Pract. Otol. (Kyoto), 84, 1541-1546.

6) Leigh, A.D. (1943) Defects of smell after head injury. Lancet, 9, 38-40.

7) Nagahara, Y. (1940) Experimentalle Studien uber die histologischen Veranderungen des Geruchsorgans nach der Olfactoriusdurchschneidung. Jpn. J. Med. Sci., 3, 165190.

8) Summer, D. (1964) Post-traumatic anosmia. Brain, 87, 107-129. 
9) Summer, D. (1975) Disturbance of the senses of smell and taste after head injuries. In: Handbook of Clinical Neurology, edited by P.H. Vinken \& G.W. Bruyn, NorthHolland Publishing Company, Amsterdam, pp. 1-25.

10) Zusho, H. (1982) Posttraumatic anosmia. Arch. Otolaryngol., 108, 90-92.

11) Zusho, H., Asaka, H. \& Okamoto, M. (1981) Diagnosis of olfactory disturbance. Auris Nasus Larynx, 9, 19-26. 